\title{
MOVER O(S) CORPO(S): ESTUDOS COMPARTILHADOS DA DANÇA NO CONTEXTO UNIVERSITÁRIO
}

Jussara Xavier ${ }^{1}$

\section{INTRODUÇÃO}

Este texto descreve processos de ensino-aprendizagem desenvolvidos nas disciplinas Teoria e Prática Pedagógica da Dança Moderna e Composição Coreográfica I, os quais resultaram na apresentação pública de dois estudos compositivos ${ }^{2}$ na primeira Semana Acadêmica do Curso de Licenciatura em Dança da Universidade de Blumenau (FURB), no dia 5 de junho de 2018. Pe(n)so, logo danço intitula o trabalho composto na disciplina Teoria e Prática Pedagógica da Dança Moderna, a partir dos princípios: peso, queda e recuperação. Dois importantes pesquisadores, teóricos do movimento, dançarinos e coreógrafos; referências no contexto da dança moderna; sustentam este estudo: 1) O austro-húngaro Rudolf Laban (1879-1958), o qual definiu o peso como um dos 4 fatores do movimento (junto ao espaço, tempo e fluxo). 2) A norte americana Doris Humphrey (1895-1958), que desenvolveu a técnica Fall and Recovery (queda e recuperação). A proposta de $P e(n) s o, \operatorname{logo}$ danço é a de dizer a dança como um campo de estudo teórico-prático de elaboração de pensamentos e movimentos, domínios nunca separados, mas em permanente conexão. Segundo o filósofo francês Jean-Luc Nancy, é impossível pensar o corpo se não o pensamos como algo que pesa (apud LOUPPE, 2012, p. 103). O corpo é peso, matéria que vive em tensão contínua com a gravidade. 0 corpo é pensamento, posto que formula suas próprias questões. Por meio de uma experiência sensível do corpo presente que pesa e pensa, buscamos explorar jogos gravitacionais e sensações decorrentes ao trabalho com o peso, a queda e a recuperação na dança. Já na disciplina Composição Coreográfica I elaboramos um estudo nomeado Procedimento 1.3, o qual teve como ponto de partida a movimentação exibida no documentário Gaga. Amor pela dança (2017), sobre o coreógrafo e diretor artístico da companhia Batsheva (Israel), Ohad Naharin. Inicialmente, a partir da escolha, estudo e leitura particular de movimentos e seus modos de

1 Doutora em Teatro (UDESC); Mestre em Artes - Comunicação e Semiótica (PUC/SP); Especialista em Dança Cênica (UDESC). Professora da Licenciatura em Dança da Universidade de Blumenau - FURB. Contato: jussarajxavier@gmail.com.

2 Docente/Diretora: Jussara Xavier. Discentes/Artistas-Criadores: Abner Cypriano, Alexandre Vieira, Ana Luiza Garcia, Ana Paula Darolt, Bruna Navarro, Caroline Noemia Rocha, Claudia Valeria Silva Schmidt Georg, Jeanne Alice dos Passos, Karoline Mohr, Larissa Kremer, Mahyra Callado, Maria Carolina Cavaco, Maria Eduarda Soares, Nathã Luiz Schug, Patrícia Schneider, Roberta Prado Guimaraes, Rodrigo de Andrade, Sandy Silveira, Stefanie Müller, Waldir Coral.

Revista "O Teatro Transcende" Departamento de Artes - CCEAL da FURB - ISSN 2236-6644 - Blumenau, Vol. 23, № 1, p. 47 - 60, 2018 - Edição Especial dos 45 Anos de Artes na FURB. 
estruturação, cada estudante desenvolveu uma composição de dança. Em seguida, tais arranjos coreográficos foram conectados entre si, produzindo um estudo compositivo conjunto.

Além de explicitar os processos de pesquisas e estudos desenvolvidos, este texto tece reflexões sobre a universidade enquanto campo de investigação, formação e produção de conhecimento em dança. A I Semana Acadêmica do Curso de Licenciatura em Dança foi importante para o compartilhamento das práticas desenvolvidas em sala de aula com a comunidade. Para o público, formado por universitários de diferentes cursos, professores de outras disciplinas da Licenciatura em Dança, familiares e amigos dos estudantes que se apresentaram e público em geral interessado em dança, revelou-se uma ocasião de acesso a saberes teóricos e práticos produzidos em um curso superior de dança. Para os acadêmicos, tal momento oportunizou uma experiência de aprofundamento dos estudos realizados e a descoberta de outras possibilidades perceptivas do corpo em movimento. Para todos os envolvidos, uma vivência propícia à troca de afetos e impressões.

\section{PE(N)SO, LOGO DANÇO, ESTUDO PRODUZIDO NA DISCIPLINA TEORIA E PRÁTICA PEDAGÓGICA DA DANÇA MODERNA}

O processo de criação foi, com certeza, muito rico, contribuindo para um crescimento pessoal enquanto professor pesquisador da dança, fazendo enxergarmos e nos apropriarmos de outras possibilidades de movimento para dança, até então inexploradas ${ }^{3}$.

No livro A filosofia da dança, a pesquisadora Marie Bardet promove um encontro entre dança e filosofia, escolhendo verbos como andar, deslizar, apresentar e compor para nomear alguns dos capítulos, os quais abordam experiências de dança em aproximação a formulações filosóficas. $O$ capítulo intitulado $P e(n) s a r$ trata da conexão entre presença do corpo e exercício do pensamento. 0 jogo de palavras diz um corpo que pesa e pensa, corpo-lugar de encontro entre prática e teoria, corpo cujo pensamento "se encontra situado por certa ancoragem em seu contexto" (BARDET, 2014, p. 24). A autora sublinha a imagem recorrente da bailarina na tradição filosófica: ser/musa leve e flutuante, elevada no ar e afastada do peso. Contudo, a evocação da leveza não recusa a presença real do corpo e a atividade concreta do pensamento, mas ressalta a relação essencial da dança com o solo e com a ação da gravidade.

\footnotetext{
A filosofia, quando convoca a dança, se situa bem no cerne dessa tensão gravitária, identificando nela aquilo que anima a própria dança. Ela retoma aqui certa oposição entre pesado e leve, mas se situa, em seu encontro com a dança, no cerne da tensão, mais do que em uma contemplação de qualquer metáfora leve da abstração. (Idem, ibidem, p. 33).
}

3 Depoimento da artista, criadora e acadêmica da Licenciatura em Dança Ana Paula Darolt a Jussara Xavier, em 20 jun. 2018.

Revista "O Teatro Transcende" Departamento de Artes - CCEAL da FURB - ISSN 2236-6644 - Blumenau, 
O Pe(n)sar de Bardet (ibidem) manifesta o paradoxo do corpo que dança na terra e no ar, associa verticalidade com horizontalidade e intensifica uma tensão entre diferenças a determinar a qualidade da dança. A autora destaca a dança como experiência do pensamento e da realidade, vivência sensível da gravidade que opera deslocamentos conceituais de/em um corpo que age no mundo. Matéria composta e atravessada pelo peso, o corpo é campo em que atuam variadas forças e sensações. Além de utilizar a proposição de Bardet (exatamente para abordar algumas questões da autora no trecho e livro apontado), o título $\mathrm{Pe}(n)$ so, logo danço remete a famosa frase do filósofo francês René Descartes (1596-1650), tradicionalmente traduzida para 0 português como "penso, logo existo". Neste sentido, trata-se de uma espécie de jogo-provocação para lançar uma discussão acerca da não-distinção entre corpo e mente, ação e pensamento, moção e emoção. E, igualmente, para olhar o corpo enquanto campo único e potencial de conhecimento, ambiente pelo qual saberes de todo tipo - filosóficos, matemáticos, sociológicos, artísticos, etc. - se encontram.

Em seus estudos acerca de diferentes qualidades do movimento, Laban relacionou quatro fatores: peso, espaço, tempo e fluência (1978, p. 36), gerados a partir de impulsos internos e presentes de modo diferenciado em quaisquer ações corporais. De modo específico, o fator peso (enfatizado no processo de composição ora descrito) refere-se a mudanças na força utilizada pelo corpo ao mover-se, diz respeito a sua intenção e sensação (FERNANDES, 2006, p. 131). Sabemos que todo corpo tem um peso (o qual corresponde a uma quantidade de quilos), contudo, interessa como o corpo usa sua força: de modo ativo (mobilizado) ou passivo (largado, não ativado). Quando ativo, o peso varia entre forte e leve; quando passivo, o peso altera-se entre fraco e pesado (ibidem, p. 131-132).

Louppe afirma que dentre os quatro fatores de Laban o peso é o mais importante, não somente por sua transferência definidora de todo movimento, mas por deslocar e construir a partir da sua própria sensação. Segundo a crítica, a queda seria uma forma de se libertar o peso, fazendo seu desfecho no contato com o solo. A poética do peso transformaria o chão em parceiro e suporte para o abandono de um corpo liberto de toda tensão em peso absoluto, e ainda, teria no chão o melhor aliado contra a atração gravitacional. Ela informa: "Inúmeros foram os textos escritos sobre a poética da queda, a começar pelos de Doris Humphrey" (LOUPPE, 2012, p. 103-106). Não à toa, Humphrey foi a segunda fonte principal no estudo desenvolvido com os acadêmicos.

Pioneira da dança moderna americana, Doris Humphrey (1895-1958) reuniu seus pensamentos e experiências coreográficas no livro The art of making dances (1980), elegendo categorias como design, dinâmica, ritmo, motivação, gesto, palavra e música como ferramentas para construir uma dança. Seus pressupostos teóricos incluem conceitos fundamentais como queda e recuperação (fall-recovery): um peso e uma força que agem no corpo fazendo-o transitar entre a possibilidade de ir ao solo e retornar à verticalidade. 
"Equilíbrio e destruição, vida e morte. Efeitos opostos que Humphrey instituiu como o princípio primeiro da sua técnica", pois para ocorrer o movimento deve-se estar "presente no arco entre dois pontos de inércia, por ela denominado de arco entre as duas mortes" (SILVA, 2005, p. 100). Nas palavras de Humphrey:

\begin{abstract}
Concebo o movimento utilizado pelo dançarino como o resultado de um equilibrio. De fato, toda a minha técnica resume-se em dois atos: afastar-se de uma posição de equilibrio e a ela voltar. Trata-se aqui de um problema bem mais complexo do que se manter em equilibrio, o que está ligado à força muscular e à estrutura corporal. Cair e se refazer (fall-recovery) constituem a própria essência do movimento, deste fluxo que, incessantemente, circula em todo ser vivo, até em suas partes mais ínfimas. A técnica que decorre destas noções é surpreendentemente rica em possibilidades. Começando-se por simples quedas no chão e voltando-se à situação vertical, descobre-se diversas propriedades do movimento que se acrescentam à queda do corpo no espaço. [...]. (apud BOURCIER, 2001, p. 270-271).
\end{abstract}

Laban e Humphrey incentivavam seus próprios alunos à análise e compreensão dos movimentos, atrelando a aquisição de conhecimentos aprofundados acerca do corpo e da dança ao desenvolvimento de práticas intensas de pesquisa e estudo. Os variados processos de trabalho e experimentos guiados por Laban ao longo de anos possibilitaram a elaboração de uma série de conceitos e princípios de orientação física e criativa, bem como, a sistematização de informações acerca da potência do corpo para o movimento. Em seu livro, Humphrey (1980) declara que suas aulas objetivavam a descoberta de novos movimentos, os quais os alunos deveriam apropriar-se para perceberem seus princípios básicos constituintes. De acordo com Cravell (2015, p. 143), é "Por causa de pessoas como Doris Humphrey", nos anos de formação da dança moderna, que "a combinação entre prática e teoria foi fermentada, uma vez que dançar não era suficiente. Humphrey era uma enorme influência para a transformação do bailarino/executor em bailarino/criador". Ainda na visão de Cravell: "Humphrey impulsionava o bailarino a desenvolver seu próprio estilo" e considerava a dança como um problema conceitual (Idem, ibidem, p. 143).

Laban e Humphrey inauguraram processos investigativos vivos e dinâmicos, cujos resultados ressoam até os dias de hoje. Apoiados nos estudos destes dois teóricos e coreógrafos; durante algumas semanas das aulas ministradas no primeiro semestre de 2018 no curso de Licenciatura em Dança; experimentamos diversas atitudes em relação ao peso corporal por meio de exercícios com peso ativo e passivo; estudos com movimentos leves, frágeis e delicados, e com movimentos firmes, pesados e vigorosos; situações de equilíbrio e desequilíbrio; diferentes indicações para arrastar, suspender e carregar o outro, ir e voltar do chão; e, ainda, práticas iniciais de Contato Improvisação $(\mathrm{Cl})$, técnica proposta pelo dançarino e coreógrafo norte americano Steve Paxton no início da década de 1970. 
Conforme já apontado, o contexto de ensino-aprendizagem e de composição de $\mathrm{Pe}(n)$ so, logo danço é a disciplina Teoria e Prática Pedagógica da Dança Moderna, contudo, a aproximação do método desenvolvido por Paxton justifica-se por ter sua estruturação no toque (o qual pode ocorrer com um peso "leve" ou "forte", relembrando Laban), no jogo e na troca ininterrupta de peso entre dois ou mais corpos; por investir na sensibilidade, presença ativa e escuta do corpo; e, ainda, por compreender mecanismos como o comportamento de um corpo em queda, a exemplo do rolamento enquanto solução para que o corpo não se machuque ao cair. Contudo, não somente nesta prática, mas também em todas as outras acima citadas, sobressaiu o compromisso de conhecer o corpo em movimento, de conscientizar-se acerca das possibilidades expressivas e motoras do corpo em estado de dança. Ademais, ainda que partindo de coreógrafos e teóricos tidos como representantes fundamentais da dança moderna, buscamos uma atualização do conhecimento, com o cuidado de pesquisá-lo no corpo sem atrelar-se a uma estética pré-determinada de dança. Interessa notar que o peso continua sendo redescoberto na dança contemporânea atual, por meio de práticas que convocam a gravidade como vetor central de ação, a condução e o passeio constante do corpo ao/pelo chão. Em nossa composição, o peso tornou-se tema, material coreográfico e justificativa para o movimento.

\title{
PROCEDIMENTO 1.3, ESTUDO PRODUZIDO NA DISCIPLINA COMPOSIÇÃO COREOGRÁFICA I
}

\begin{abstract}
Havia em mim dúvida em relação a forma com que o público iria receber nossa performance, até porque não se tinha noção exata de quem estaria na plateia. [...] chamou a atenção um comentário vindo de uma antiga colega da Pós-graduação em Dança Educacional: "Viemos de Agrolândia imaginando assistir uma coisa e presenciamos algo totalmente diferente, que nos fez refletir...." Por certo saímos das confortáveis caixinhas que já nos pertenciam para experimentar algo diferente, sensações brotaram [...] quando estava compondo a partir do documentário Gaga, levar o princípio de bater no próprio corpo ao extremo e "ter saído de mim" foi bem interessante... ${ }^{4}$
\end{abstract}

Procedimento 1.3 é uma reunião de breves composições realizadas em aula, as quais obedeceram a uma sequencia de instruções, a realização de tarefas individuais e coletivas. 0 impulso inicial foi 0 compromisso de assistir ao documentário Gaga. Amor pela dança (2017), sobre o coreógrafo israelense Ohad Naharin $^{5}$ (1952) e escolher cinco posições estáticas e/ou pequenas sequencias de movimentos com início, meio e fim presentes no filme. Tais movimentos deveriam ser decorados para posterior demonstração em sala de aula. Desde o início do semestre, o vídeo acima intitulado encontrava-se em exibição na provedora Netflix. Mesmo após várias recomendações, praticamente ninguém da turma assistiu ao documentário. Sendo assim,

\footnotetext{
4 Depoimento da artista, criadora e acadêmica da Licenciatura em Dança Cláudia Schmidt Georg a Jussara Xavier, em 20 jun. 2018. ${ }^{5}$ Coreógrafo e diretor artístico da companhia de dança Batsheva, de Tel Aviv, Israel, desde 1990. A Batsheva Dance Company foi fundada como uma companhia de repertório em 1964 pela Baronesa Batsheva de Rothschild, que recrutou Martha Graham como primeira diretora artística. Desde 1989, a sede da companhia é o Suzanne Dellal Center, em Tel Aviv. Fonte: Batsheva Dance Company. Disponível em: https://batsheva.co.il/en/about?open=the_company. Acesso em: 14 jun. 2018.
} 
escolhi iniciar uma atividade de composição tornando o acesso à produção obrigatório. Inicialmente, 0 propósito foi o de estimular o conhecimento da trajetória profissional de um importante coreógrafo; acessar suas escolhas conceituais, filosóficas e artísticas; descobrir seus modos de trabalho, suas parcerias, dificuldades e sucessos. Contudo, ao solicitar a escolha e o aprendizado de movimentos fixos ou em deslocamento, desejei que os estudantes se apropriassem do conhecimento de modo encarnado e reflexivo, ou seja, que transformassem a dança do outro em algo vivo em si mesmos. As escolhas deveriam ser apresentadas aos colegas em sala, manifestadas por meio de gestos e falas, pois além de dançá-las, deveriam argumentar e justificar suas preferências, bem como, descrever os caminhos e gestos do corpo. Em conjunto, após cada exibição individual, realizamos um exercício de investigação e leitura do corpo em ação, buscando compreender e relatar a situação e mecânica do corpo ao executar cada movimento. Assim, os estudantes listaram o que denominamos como regras, princípios e/ou proposições para geração de movimentos. Dentre muitos deles constaram os seguintes: corpo em colapso, corpo abandonado, jogo entre equilíbrio e desequilíbrio, dobra e extensão, conexão cabeça e quadril/cotovelo e joelho/ombro e joelho, manipulação de partes do corpo, instabilidade, cabeça como ponto de apoio, imobilização dos braços, saltos, mínimo contato com o chão, pequenas explosões, batidas contínuas do corpo no chão, nível baixo, caminhada em quatro apoios, sustentação, saltos com peso para baixo, tempo muito lento/rápido, transferência de peso, joelhos sempre dobrados, palmas da mão viradas para frente, múltiplos focos, mudança súbita de direção, sustentação, mudança de apoios, antebraço/cotovelo como apoio, pernas cruzadas, pausa, repetição e ampliação do movimento, mão e cotovelo na mesma altura, meia ponta, direção opostas, cabeça sempre em movimento. E, ainda, a criação de movimentos a partir dos verbos: arquear, torcer, deslizar, girar, ondular, empurrar, rolar, ondular, cortar (o ar), socar, lançar (braços/peito), tremer, sustentar, tensionar, acelerar e movimentar (somente uma parte do corpo). Foi interessante descobrir posteriormente que algumas proposições, a exemplo do corpo em colapso, são parte essencial da linguagem Gaga ${ }^{6}$, desenvolvida por Ohad Naharin junto ao Batsheva Dance Company. Nas palavras do coreógrafo: "Em Gaga, temos um termo que diz "colapso em movimento". Na verdade, significa que não somos moldados pela gravidade; somos moldados por uma força que se opõe à gravidade. A importância do colapso é ajudá-lo a medir a força que você precisa para se opor e brincar com a gravidade"7.

\footnotetext{
6 Ohad Naharin não considera Gaga como uma técnica, mas como uma "caixa de ferramentas" ou como uma "linguagem que evolui". Fonte: Entrevista da escritora e crítica Martha Schabas com Ohad Naharin publicada no site The Globe and Mail. Disponivel em: $\mathrm{https://www.theglobeandmail.com/arts/theatre-and-performance/choreographer-ohad-naharin-on-developing-the-dance-language-}$ gaga/article33531396/. Acesso em: 3 abr. 2018.

7 Entrevista da escritora e crítica Martha Schabas com Ohad Naharin publicada no site The Globe and Mail. Disponível em: https://www.theglobeandmail.com/arts/theatre-and-performance/choreographer-ohad-naharin-on-developing-the-dance-languagegaga/article33531396/. Acesso em: 3 abr. 2018.
} 
Outras noções exploradas em Procedimento 1.3 são a de roubo e reprodutibilidade, especialmente presentes nas artes visuais contemporâneas a partir da década de 1980, juntamente com a morte da ideia de originalidade. Mais e mais, há um excesso de informações e imagens em circulação, as quais se reproduzem de modo frenético e livre pelo mundo. A troca gratuita de músicas, vídeos, livros, textos e arquivos diversos na internet colaboram para a destruição dos direitos autorais. Ainda que, paradoxalmente, o individualismo siga em expansão neste contexto, a ideia de originalidade avança perdendo sentido e o questionamento de sua validade contamina múltiplas esferas artísticas. Produções de música, cinema, vídeo, teatro, dança, artes visuais e literatura, se apropriam do passado e organizam releituras que citam, dialogam, comentam, criticam, homenageiam, ironizam, enfim, referenciam de modo imprevisível algo já criado, já feito. Trata-se de uma rejeição à ideia de autoria exclusiva ${ }^{8} \mathrm{e}$, simultaneamente, do reconhecimento de um mundo de conhecimentos ricos e pouco explorados. Já na década de 1930, o artista revolucionário francês Marcel Duchamp (1887-1968) mostrava ao mundo o seu desdém com o caráter único de uma obra de arte. Ele realizava várias peças de uma mesma produção para ampliar as modalidades de disseminar sua arte. Ao revisitar, reconstruir ou fazer diferentes versões de suas próprias obras, Duchamp dialogava com a reprodutibilidade da informação corrente no mundo. Na esteira deste pensamento e na segunda metade do século XX, Andy Warhol (1928-1987); principal expoente da Pop Arte americana; criou uma série de pinturas com imagens repetidas. Esta produção mecânica de imagens já "consumidas" pelo público, provocou um diálogo entre arte, bens da sociedade de consumo e elementos da cultura de massa.

Ao propor uma composição coreográfica a partir de movimentos prontos de um coreógrafo internacionalmente reconhecido, chamei atenção ao potencial de aprendizado e descoberta presentes na cópia e na repetição. Apresentei aos estudantes o livro Roube como um artista. 10 dicas sobre criatividade, de Austin Kleon (2013), que recorda o óbvio: pessoas aprendem a escrever copiando letras e alfabeto, pintores aprendem a pintar reproduzindo obras-primas, os Beatles começaram como uma banda cover. $O$ autor cita sentenças de grandes artistas, como o pintor Salvador Dali: "Aqueles que não querem imitar nada, produzem coisa alguma"; a estrela do basquete Kobe Bryant: "Não há uma jogada que seja uma jogada nova"; o estilista Yohji Yamamoto: "Comece copiando o que você ama. Copie copie copie copie. Ao final da cópia, você encontrará a si mesmo"; o escritor Glenn O'Brien: "Você começa como um impostor e torna-se real"; o cantor e compositor David Bowie: "A única arte que estudarei é aquela que contém o que eu possa roubar"; dentre outras (apud KLEON, 2013). Nós - bailarinos, sabemos muito bem o que significa copiar e repetir passos em aulas de dança como metodologia para aprender. Contudo, no caso relatado, o foco não se esgotou na mera

\footnotetext{
${ }^{8}$ No campo das artes e da filosofia, a discussão sobre a ideia de autoria é ampla. 0 conceito de autor foi discutido por importantes pensadores do século XX, tais como Roland Barthes, no ensaio A morte do autor, de 1988; na conferência O que é um autor?, de 1969, por Michel Foucault; e na obra Profanações, de Giorgio Agamben.
} 
mimetização de movimentos ou naquilo que chamamos de plágio, mas numa investigação que abarcou a repetição da forma para além da aparência, que investigou o funcionamento do corpo e a condução do movimento, que internalizou um modo específico de compreensão da dança e do mundo. Tratou-se mais de emulação e menos de imitação: "Emulação é quando a imitação dá um passo adiante e ganha a sua própria forma" (KLEON, 2013, p. 46). De olho na transformação dos movimentos assinados por Ohad Naharin no filme Gaga. Amor pela dança, os acadêmicos estudaram, transformaram e criaram suas próprias partituras coreográficas a partir de três indícios físicos escolhidos dentre os diversos encontrados (cada estudante selecionou os seus para compor uma dança solo).

A (re)montagem de repertórios coreográficos é bastante usual no mundo da dança clássica. O Lago dos Cisnes, $O$ Quebra-Nozes e A Bela Adormecida nomeiam algumas das peças tradicionais mundialmente famosas, as quais ganharam versões em palcos do mundo inteiro. Não à toa, existem cursos específicos de balé clássico de repertório, normalmente para turmas tecnicamente mais avançadas. Já no território da dança contemporânea, algumas companhias costumam remontar os próprios espetáculos de tempos em tempos, a exemplo de Mix, da Companhia de Dança Deborah Colker. Tal montagem estreou em 1996 e foi remontada em 2000, 2006, 2010 e 2015 com bailarinos diferentes, mantendo o mesmo cenário, figurino e trilha ${ }^{9}$. No âmbito formativo, a estratégia de montagem e remontagem é potente recurso de treinamento técnico e criativo. Por meio de tal ferramenta, o aprendiz pode incorporar informações diversas, acessar outras corporeidades e modos de organização compositiva, ampliando o próprio repertório motor e afetivo. De acordo com Gadelha,

O estudo de repertórios - estes entendidos de maneira ampla - pode figurar assim como um potente elemento [...] que [...] permitirá ao bailarino em formação constituir um corpo capaz de escrituras próprias. Conectando-se mediante obras coreográficas à corporeidade do outro, vivenciando-a em seu próprio corpo, nesse processo dialógico de encontro com a alteridade, 0 jovem bailarino estará continuamente a (re)construir sua história corporal, sua forma de perceber e organizar o corpo no movimento dançado, sua maneira de gestar a dança. Por operações distintas, que poderão acontecer tais quais montagens inéditas conduzidas por coreógrafos convidados, remontagens de obras do repertório de um grupo ou coreógrafo, estudos e encenações de obras históricas referenciais, 0 aluno estará acessando um presente e um passado povoados de gestos artísticos, constituídos e constituintes de corporeidades dançantes. [...] Seja qual for a natureza do repertório trabalhado, o processo de acesso a ele deve ser o mais amplo possível, permitindo ao jovem artista não apenas se apropriar de gestos, contudo visualizar, compreender e incorporar os diversos vetores de forças presentes na gênese deles, sejam estes de obras já preexistentes ou em fase de criação. [...] a apropriação do gesto do outro se fará sempre uma escritura com o gesto do outro, um elemento a mais para a produção do gesto próprio. (2014, p. 98-99).

${ }^{9}$ Conforme entrevista da diretora Deborah Colker veiculada no Portal de notícias G1, matéria intitulada Criação de Deborah Colker, balé vertical é apresentado em Campinas. Disponivel em: http:/g1.globo.com/sp/campinas-regiao/noticia/2015/05/criacao-dedeborah-colker-bale-vertical-e-apresentado-em-campinas.html. Acesso em: 9 jul. 2018. 
O processo individual de remontar movimentos dos bailarinos dirigidos por Naharin foi o impulso inicial para a criação de movimentações autorais por parte de cada discente. Com o objetivo de apresentação na primeira Semana Acadêmica do Curso de Licenciatura em Dança, reuni as diferentes composições solo de modo quase aleatório, com algumas indicações: formação de grupos de três pessoas; manutenção das posições no espaço em forma triangular; ausência de contato corporal direto entre os bailarinos; criação de um comum (exemplos: uma pausa simultânea dos três intérpretes-criadores em um momento determinado, a repetição de um mesmo gesto por todos), o qual deveria ser encontrado/criado pelo próprio trio. Após 0 término de cada composição, o grupo saía de cena para dar lugar ao próximo. 0 ambiente sonoro da dança foi uma voz masculina lendo um trecho do audiolivro em inglês intitulado Dance Dance Dance, do escritor japonês Haruki Murakami. Tal escolha foi testada somente no momento da apresentação, como um modo de oferecer uma nova pergunta aos corpos em cena e verificar como cada um lidaria com a nova informação. Vale esclarecer que todo o processo criativo foi realizado com ausência de sons, dado que o foco foi o de obedecer estritamente as regras escolhidas para viabilizar a pesquisa e composição de outras corporeidades. Assim, surgiu Procedimento 1.3.

\title{
SEMANA ACADÊMICA DE DANÇA
}

\begin{abstract}
A apresentação na Semana Acadêmica foi muito significativa tanto em termos de aprendizado quanto no sentido de imersão na proposta. [...] ouvir como o estudo atingiu quem estava assistindo foi muito importante para saber o que provocamos [...] conseguimos ter uma noção mais clara pelos feedbacks da troca de energia que ocorreu e as sensações causadas através de um estudo que é bem diferente das propostas de apresentações que acontecem frequentemente [...] toda essa experiência e troca entre nós acadêmicos, professores e demais participantes fez com que eu refletisse muito sobre o que venho fazendo e que acredito enquanto dança ${ }^{10}$.
\end{abstract}

O curso universitário de dança de Blumenau pode ser examinado como um mundo cultural e social em permanente transformação, estruturado por saberes e fazeres complexos, a constituir uma identidade relativamente partilhada e móvel. Em suas realizações, a sociedade universitária ou comunidade acadêmica viabiliza, adequa e até mesmo desvia-se do projeto inicialmente proposto, costurando efetuações, questionamentos e ajustes do projeto fundador do curso. É importante ressaltar que a implementação do curso de Licenciatura em Dança ocorre no segundo semestre de 2017 e já neste primeiro ano de surgimento organiza-se a Semana Acadêmica, com a participação efetiva das suas duas turmas de alunos (1a e $2^{\mathrm{a}}$ fase) e de professores da graduação. Trata-se, portanto, de um curso em fase de implantação, o qual reúne docentes

10 Depoimento da artista, criadora e acadêmica da Licenciatura em Dança Stefanie Muller a Jussara Xavier, em 20 jun. 2018.

Revista "O Teatro Transcende" Departamento de Artes - CCEAL da FURB - ISSN 2236-6644 - Blumenau, 
e discentes num processo recente de encontros, descobertas e aprendizados. Neste contexto, a oportunidade de preparação e organização da Semana Acadêmica foi propícia para intensificar momentos diferenciados de troca e colaboração, forjando espaços de integração e vivências favoráveis a amizade e elaboração de conhecimento em dança. Realizou-se não apenas uma "semana" de formação complementar com oportunidades diferenciadas de qualificação, mas ações afetivas, motivacionais e que confirmam o caminho formativo recentemente iniciado. Para os estudantes foi uma ocasião para realização de uma experiência no sentido etimológico do termo: tentativa, aventura, risco, passagem, transporte, perigo. Em depoimentos escritos após as apresentações dos estudos na Semana Acadêmica, alguns alunos revelaram certa hesitação em mostrar as composições ao público, outros confidenciaram sensações de comoção e surpresa e, ainda, 0 desejo de continuidade da experimentação iniciada. As falas reproduzidas a seguir são exemplificativas.

Achei interessante a partilha com a universidade do trabalho feito em sala. Foi um desafio para mim, pois antes de entrar em cena fiquei com receio de fazer o que eu havia trabalhado em sala de aula, por ser diferente talvez do que eles "estavam esperando". [...] 0 resultado foi muito bom, referente aos comentários que foram surgindo do público no final da apresentação. Acho que foi além do que esperávamos, alcançamos um olhar muito importante para o mundo da dança ${ }^{11}$.

[...]. havia um receio de como isto ficaria em cena, não só pelas propostas que fogem ao convencional no que o público geralmente espera de um espetáculo de dança, mas também pelo pouco tempo de ensaio/organização e grande quantidade de pessoas e ideias envolvidas. [...] Foi algo contagiante, de fazer e olhar, que despertou inúmeros significados, sentimentos e reflexões ${ }^{12}$.

[...] Essas novas experiências referem-se a poder dançar algo que nunca tinha feito antes [...]. Acredito que esta composição tocou muito o público que estava assistindo, mas também tocou quem estava dançando. Surgiram muitos comentários interessantes, coisas que eu nem tinha imaginado da nossa composição, e que me fizeram refletir o quanto o olhar do outro pode ser diferente do meu, e isso foi muito bom, pois me abriu às possibilidades que nossa composição poderia ter ${ }^{13}$.

Nosso trabalho foi diferente de tudo o que eu já tinha apresentado até hoje, e ter conseguido chegar até o fim foi gratificante e me mostrou o quanto podemos evoluir em pesquisa. Recebemos um feedback maravilhoso [...]. Tudo isso é motivo para continuarmos a pesquisar e querer saber mais $^{14}$.

Os processos pelos quais passamos para as criações foram muito intensos, e com certeza ressoarão por muito tempo nos quesitos pessoais e profissionais. [...] o processo de dança moderna foi o que mais mexeu comigo, de modo estésico e sinestésico, mesmo antes da resposta do público, que foi muito positiva. Sai da semana acadêmica e dos processos com a sensação de querer mais, uma necessidade de continuação dos processos (o que não era tão comum a mim) ${ }^{15}$.

\footnotetext{
11 Depoimento do artista, criador e acadêmico da Licenciatura em Dança Alexandre Vieira a Jussara Xavier, em 20 jun. 2018.

12 Depoimento da artista, criadora e acadêmica da Licenciatura em Dança Ana Paula Darolt a Jussara Xavier, em 20 jun. 2018.

${ }^{13}$ Depoimento da artista, criadora e acadêmica da Licenciatura em Dança Larissa Kremer a Jussara Xavier, em 20 jun. 2018.

${ }^{14}$ Depoimento da artista, criadora e acadêmica da Licenciatura em Dança Caroline Noemia Rocha a Jussara Xavier, em 20 jun. 2018.

15 Depoimento do artista, criador e acadêmico da Licenciatura em Dança Rodrigo de Andrade a Jussara Xavier, em 20 jun. 2018.
}

Revista "O Teatro Transcende" Departamento de Artes - CCEAL da FURB - ISSN 2236-6644 - Blumenau, 
Destaco nos discursos acima sentenças como "dançar algo que nunca tinha feito antes" e fazer um trabalho "diferente de tudo o que eu já tinha apresentado até hoje", as quais revelam um modo específico de dançar usual ao grupo em questão: a junção de passos fixos e determinados para acompanhar uma música ou, dito de outra maneira, movimentos padronizados organizados em coreografias de curta duração, as quais seguem tanto os modelos disseminados pelas academias (em que alunos repetem os movimentos idealizados e realizados pelo professor) quanto a lógica difundida pelos festivais competitivos catarinenses (em que 0 vencedor dita a fórmula a ser copiada). Ao apontar que dançamos algo diverso do "que o público geralmente espera de um espetáculo de dança", percebe-se a crença de que a plateia deseja assistir sempre o mesmo: representações dominantes de dança, quer dizer, associações normativas e miméticas de movimentos harmonizados ao som de uma música.

Em contraposição, denuncia-se o mote de uma experiência: causar alguma espécie de desconcerto e interromper comportamentos rotinizados e repetitivos, ou seja, gerar deslocamentos, suscitar desvios, provocar a percepção. Nos dois estudos compositivos produzidos e exibidos, os acadêmicos foram chamados à constituição de outras corporeidades. No primeiro trabalho, toda a movimentação deveria surgir da consciência e sensação do corpo em mobilizar o peso, de modo solo e em contato com o outro (corpo, parede, atmosfera, chão, etc.). Ou seja, o estudo só funcionaria na medida do comprometimento individual em abarcar uma experiência no sentido de permitir que o movimento ocorresse como ação, e não como representação mecânica, quer dizer, não como reprodução de passos pré-concebidos de dança. Também no segundo trabalho, cada intérprete deveria atentar para seguir estritamente os próprios princípios de movimentação escolhidos, mantendo a pesquisa em cena e simultaneamente, uma conexão com aqueles que condividiam 0 espaço de exibição. Em ambos os casos, a expressão estava localizada no modo de comportamento do corpo em estado de dança, ou seja, na composição de uma experiência, em detrimento a uma mostração formal de sequencias coreográficas decoradas. A experiência

[...] somente tem sentido no modo como configura uma personalidade, um caráter, uma sensibilidade ou, em definitivo, uma forma humana singular de estar no mundo, que é por sua vez uma ética (um modo de conduzir-se) e uma estética (um estilo). Por isso, também o saber da experiência não pode beneficiar-se de qualquer alforria, quer dizer, ninguém pode aprender da experiência de outro, a menos que essa experiência seja de algum modo revivida e tornada própria. [...] a lógica da experiência produz diferença, heterogeneidade e pluralidade. [...] a experiência tem sempre uma dimensão de incerteza que não pode ser reduzida. Além disso, posto que não se pode antecipar o resultado, a experiência não é o caminho até um objetivo previsto, até uma meta que se conhece de antemão, mas é uma abertura para o desconhecido, para o que não se pode antecipar nem "pré-ver" nem "pré-dizer". (BONDÍA, 2002, p. 27-28).

Na esteira do pensamento de Bondía, o saber da experiência é um saber particular, subjetivo, relativo, contingente, pessoal. Quer dizer, a experiência não é simplesmente o que acontece, mas o que acontece a 
alguém, modificando-o. Assim, ainda que diante de um mesmo acontecimento ou de uma mesma proposta compositiva, cada um foi convocado a fazer uma experiência - singular e sem possibilidade de repetição (BONDÍA, 2002, p. 27). Neste contexto, as apresentações dos estudos na Semana Acadêmica de Dança significaram um processo de aprendizagem transformador, sustentado por um pensamento formativo que opera na negociação entre corpo e ambiente e, sendo assim, é alimentado pelas oportunidades de diálogo e reflexão. Acadêmicos-intérpretes-criadores e público acionaram conceitos e saberes da dança por meio da ação e interação. Tal prática conectiva destacou o compromisso de formar um professor-artista-pesquisador na graduação em dança da FURB, curso constituído enquanto Licenciatura que aposta no diálogo intensivo entre as dimensões pedagógica e artística. Ao propor processos complementares de pesquisa, composição, apresentação e discussão de estudos em dança; num trânsito contínuo entre pensar e fazer; buscamos (re)descobrir o laço entre prática educacional e produção artística, afastando a falsa dicotomia entre criação poética e ensino da dança. No papel de docente-diretora, assumo a responsabilidade de orientar o discenteartista a

[...] acreditar na sua individualidade, a encontrar o caminho da sua potência criativa [...]. Esse caminho é então construído no espaço entre 0 aluno e o professor, tocado inicialmente a quatro mãos e, mais adiante, a muitas mãos e tantos corpos quantos forem aqueles dos trabalhos em grupo. Isso só é possível mediante a aplicação dos conteúdos relacionados do curso, entre as disciplinas práticas, teóricas e criativas, pois atualmente se busca uma interseção de todos esses saberes, que não mais são lecionados de forma estanque, como no modelo ultrapassado dos currículos antigos. (SILVA, 2016, p. 34).

Independentemente àquilo que conhecemos como técnica de dança (clássica, moderna, contemporânea, popular, de rua, de salão, etc.) e as muitas diferenças que brotam do trabalho com cada uma delas, sublinhamos que cada experiência técnica desenha uma corporeidade específica. Assim, para um acadêmico da Licenciatura em dança é fundamental compreender que uma prática orientada de dança molda tanto um jeito particular de se movimentar (estética) quanto uma visão do mundo (ética). E, ainda, assimilar o corpo como processo, dado que ele forma e, simultaneamente, é formado por uma cultura. No período da graduação universitária os alunos acessam teorias e práticas singulares de dança, mas mais do que dominar uma língua particular (algo que necessitaria de um estudo aprofundado e um tempo dilatado), pretende-se que percebam as variadas possibilidades oferecidas pelas mesmas e as utilizem em interação dinâmica com 0 ambiente. Portanto, as técnicas não são tratadas como metodologias estagnadas e datadas, ao contrário, são exploradas em função de seu potencial de transformação no presente. Sublinha-se a necessidade de

[...] operar deslocamentos no pensamento, permitindo a emergência de novas possibilidades, de caminhos outros. Não se trata de erros ou acertos, porém apenas de aprender dança como 
exercício de si, como uma estética da existência [...] é preciso, além disso, viver a dança produzida pelo sujeito, em seu próprio ato de construir-se a si mesmo, viver a experiência de pensamento no próprio pensamento: um aprender como exercício de si sobre si mesmo, singular, mas nunca solitário, não mediado apenas por formas transmissíveis, porém, sobretudo, por uma espécie de convivência, por um estar junto. [...] se trata de [...] mobilizar a instituição para que ela seja capaz de reinventar-se com o movimento [...]. (PRIMO, 2016, p. 204-205).

Trata-se, afinal, de mover o(s) corpo(s) incentivando-o(s) a práticas de convivência, de exercitar a dança como pensamento e reconfiguração do mundo.

\section{REFERÊNCIAS}

BONDIA, Jorge Larrosa. Notas sobre a experiência e o saber da experiência. Revista Brasileira de Educação. Tradução: João Wanderley Geraldi. Rio de Janeiro, n.19, Jan./Abr. 2002, p. 20-28.

BOURCIER, Paul. História da dança no ocidente. Tradução de Marina Appenzeller. São Paulo: Martins Fontes, 2001.

CRAVELL, Holly Elizabeth. Dando corpo à história. Curitiba: Prismas, 2015.

FERNANDES, Ciane. 0 corpo em movimento: 0 sistema Laban/Bartenieff na formação e pesquisa em artes cênicas. 2. ed. São Paulo: Annablume, 2006.

GADELHA, Ernesto. Repertórios coreográficos e formação em dança: uma reflexão acerca do papel da (re)montagem de obras na formação em dança contemporânea. Em: Instituto Festival de Dança de Joinville (Org.). A dança clássica: dobras e extensões. Joinville: Nova Letra, 2014. p. 91-99.

HUMPHREY, Doris. The art of making dances. 19. ed. New York: Grove Press, 1980.

KLEON, Austin. Roube como um Artista: 10 dicas sobre criatividade. Tradução de Leonardo Villa-Forte. Rio de Janeiro: Rocco, 2013.

LABAN, Rudolf. O Domínio do Movimento. Tradução de Anna Maria Barros De Vecchi e Maria Sílvia Mourão Netto. São Paulo: Summus Editorial, 1978.

LOUPPE, Laurence. Poética da dança contemporânea. Tradução de Rute Costa. Lisboa: Orfeu Negro, 2012. PRIMO, Rosa. Por uma graduação em dança como exercício de si. Em: ROCHA, Thereza; Instituto Festival de Dança de Joinville (Orgs.). Graduações em dança no Brasil: o que será que será? Joinville: Nova Letra, 2016. p. 201-205.

SILVA, Eliana Rodrigues. Dança e pós-modernidade. Salvador: EDFBA, 2005. 
Graduação em dança no Brasil: professor como orientador e aluno como protagonista. Em: ROCHA, Thereza; Instituto Festival de Dança de Joinville (Orgs.). Graduações em dança no Brasil: 0 que será que será? Joinville: Nova Letra, 2016. p. 29-36.

XAVIER, Jussara; MEYER, Sandra; TORRES, Vera (Org.). Tubo de Ensaio. Composição [Intervenções + Interseções], Instituto Meyer Filho, Florianópolis, 2016. 